\title{
La economía política del encuentro entre el mundo islámico y el occidental
}

\section{Juan E. Iranzo y Gregorio Izquierdo}

\section{INTRODUCCIÓN}

A lo largo de la década pasada se rompieron dos dualidades tradicionales que se mantenían desde la finalización de la Segunda Guerra Mundial. La separación entre Occidente y el Este, y el enfrentamiento Norte-Sur. La caída del socialismo real y la aparición de países emergentes han sido las causas de esta ruptura, lo que favorece una economía global con más oportunidades, pero también con más retos, que se ha visto posibilitada por las tecnologías de la información y comunicación. Estos procesos tienden a incrementar la comunicación y la capilaridad social, cultural y económica. Frente a esta realidad surgen posturas radicales, como el terrorismo fundamentalista, que no ofrecen soluciones, sino enfrentamiento, y producen efectos dramáticos con resultados perversos.

\section{EL RESURGIMIENTO ISLÁMICO COMO RESPUESTA AL NACIONALISMO Y A LA FALTA DE DEMOCRACIA}

El socialismo autoritario con el que los regímenes nacionalistas accedieron al poder, tras los procesos de descolonización, fracasó en su intento de solventar las necesidades materiales básicas de sus pueblos. La inercia expansiva de las 
burocracias improductivas desembocó en un intervencionismo asfixiante, indeseables niveles de corrupción y la presencia generalizada de empresas públicas en ámbitos clave del tejido productivo, como los sectores industrial o financiero, con la consiguiente rémora para el progreso económico y el empobrecimiento de las sociedades.

El descontento popular por el fracaso de los nacionalismos árabes fortaleció a los movimientos de oposición, que, sin disponer apenas de otras alternativas viables, el fundamentalismo islámico canalizó en su provecho, lo que obligó cada vez más a potenciar los aparatos militares de estos regímenes. Los intentos por frenar este avance mediante la represión fragmentaron las sociedades y alimentaron las espirales de violencia, tal y como sucedió en Argelia durante la década de los noventa, donde ante el avance electoral del fundamentalista FIS se produjo un golpe de Estado militar que desembocó en una guerra civil encubierta que causó más de cien mil víctimas. De igual forma, el expansionismo iraquí se puede entender como una huida hacia delante del régimen baasista de Sadam Hussein para aumentar coercitivamente sus recursos petrolíferos, primero contra Irán y luego contra Kuwait, ante su incapacidad de financiar su régimen militarista, necesario para sofocar los diversos conflictos internos.

Los regímenes democráticos y el pluralismo político que caracterizan al mundo occidental tampoco han funcionado en el mundo islámico, donde el poder se ejerce casi siempre autoritariamente, sin la disciplina de la reelección resultante del apoyo ciudadano, con la consiguiente legitimación para la alternativa fundamentalista. El problema es que la viabilidad democrática suele requerir de amplias clases medias que den estabilidad al sistema y permitan una cierta alternancia en el poder. De igual forma, es importante que se respeten los derechos fundamentales con normas prevalentes constitucionales, y una independencia de los poderes que evite que se pueda utilizar el acceso al poder por vía democrática para suprimir la misma a partir de entonces.

En ausencia de un marco institucional de esta índole, el inasumible riesgo político colapsa permanentemente el desarrollo por la vía de desestimular la inversión y la asunción de riesgos y obliga a un gasto excesivo en defensa, para sostener políticamente los regímenes y no quedar relegados en las carreras armamentistas registradas, del orden del 12 por 100 de su producto frente al 4 por 100 del mundo occidental (Miguel, 2000), con el consiguiente sacrificio del resto de las necesidades públicas, como, por ejemplo, de la construcción de infraestructuras económicas o de los gastos sociales, cuya falta de provisión deja así un hueco a la acción de las instituciones religiosas. 


\section{EL DESENCUENTRO ENTRE EL MUNDO ISLÁMICO Y EL OCCIDENTAL}

La guerra del Golfo y la escalada de las acciones del terrorismo fundamentalista han generado una conciencia de cierto desencuentro entre los mundos islámico y occidental. Este posible choque de civilizaciones (Huntington, 2001, p. 252) responde a una diversidad de factores entrelazados, pero de naturaleza muy heterogénea. Entre las causas políticas hay que señalar la involución de la civilización islámica hacia el pasado y su vuelta a los valores tradicionales, con la consiguiente exclusión de los modelos sociales occidentales, con el deseo de preservar la integridad de la cultura y de los valores islámicos, y la consolidación de la primacía militar de Estados Unidos en la región tras el hundimiento del comunismo y la rápida resolución de las guerras contra Irak y Afganistán. Dado que existen múltiples estudios sobre estas motivaciones (Martínez, 1997; Kepel, 2001), nosotros nos vamos a centrar en los puntos de fricción de carácter más estrictamente económico.

\section{A. La brecha demográfica}

El crecimiento demográfico del mundo islámico ha sido en la década de los noventa de los más altos del mundo, 2,2 por 100 anual (frente al 0,7 por 100 del mundo desarrollado), como consecuencia ante todo del bajo nivel de desarrollo y de la discriminación que sufre la mujer en el acceso a la educación y al empleo por las normas religiosas y culturales, lo que ya de por sí supone una reducción del potencial productivo (Banco Mundial, 2001). Como efecto de esta espiral demográfica, la mayor parte de la población es extremadamente joven y dependiente, lo que, por un lado, impide que se generalicen los esfuerzos de educación y ahorro y, por el otro, alimenta la pobreza y las hambrunas, sobre todo en las sobrepobladas ciudades.

El mundo árabe, a pesar del carácter primario de sus sociedades, es incapaz de abastecerse alimentariamente y de acompañar el aumento de la población con un correlativo aumento de la renta que permita atender las necesidades materiales de la misma, lo que alimenta de forma permanente dos fenómenos que tensionan las relaciones del Magreb y de Oriente Medio con Occidente: por un lado, las presiones migratorias hacia el exterior, cuyo creciente ritmo se ha vuelto inasumible para los países occidentales receptores, que como respuesta se han visto obligados a cerrar fronteras, y, por el otro, una tendencia hacia una radicalización de la sociedad hacia el fundamentalismo como motor de cambio político ante la ausencia de alternativas democráticas. 


\section{B. La religión como mecanismo de orientación politica}

La doctrina islámica no está en principio enfrentada con el progreso económico, aunque sí lo estén algunas prácticas y aplicaciones reales de algunos de sus seguidores más radicales, como, por ejemplo, la discriminación de la mujer, las limitaciones del Corán al cobro excesivo de intereses o la supresión de las libertades resultante de supeditar la totalidad de la acción social humana a la práctica religiosa, y no dudan en utilizar la violencia para generalizar la aplicación de sus principios. En estos casos en que la religión condiciona en exceso la totalidad de las facetas de la vida humana, se contribuye a perpetuar el subdesarrollo, a no ser que el modelo se vea obligado a flexibilizarse ante el debilitamiento de sus bases como resultado del deterioro del bienestar material, tal y como está sucediendo en la actualidad en Irán, con el ascenso del clérigo reformista Jatami. Así pues, la posible vinculación del islamismo con la pobreza se deriva ante todo del seguimiento forzado de sus corrientes más extremas, más que de la religión propiamente dicha, como guía de orientación espiritual, por lo que el subdesarrollo no se puede identificar de forma exclusiva con el factor religioso, ya que la expansión del fundamentalismo en muchos países es más la consecuencia del subdesarrollo que su causa (Sachs, 2001).

La generalización de la pobreza extrema y la incapacidad para satisfacer las necesidades básicas alimenticias generan sentimientos de frustración, cuya responsabilidad se achaca en general al exterior. El problema es que se alimenta un círculo vicioso en el que para superar el subdesarrollo resultante de sus erróneas opciones involucionistas, éstas se radicalizan aún más aislándose económica y culturalmente del mundo exterior. Para estos planteamientos, la interconexión económica y cultural de la globalización constituye una amenaza para sus modelos de sociedad, que se anclan en el pasado aprovechándose del fatalismo cultivado por el integrismo a través de la desinformación e irracionalidad de las clases más empobrecidas (Garaudy, 2001, p. 15). Tal y como se ha dicho, "el objetivo de los fundamentalistas es estar desconectados de todo excepto de su fuente de verdad» (Friedman, 1999).

Por todo ello, es importante diferenciar entre desarrollo y occidentalización, ya que el mundo islámico debe poder conciliar la conservación de sus principios definitorios, como civilización, con el aprovechamiento de instituciones del resto del mundo que contribuyen a su bienestar social. Es inmoral rechazar los cauces que llevan al desarrollo como excusa para preservar otros valores pretendidamente superiores, como los de las tradiciones o los exclusivamente espirituales, máxime cuando generalmente se priva a las personas afectadas de la posibilidad de elegir, y es que, tal y como ha señalado el Nobel de Economía Amartya Sen, el desarrollo exige de la superación de todas las causas de privación de la libertad, tanto la pobreza como la intolerancia e intervencionismo de los Estados represivos. 


\section{Los precios del petróleo}

El punto económico de fricción más visible entre ambos mundos se manifiesta a través de los intentos de modificar en su provecho los precios del petróleo, que constituye su vínculo económico más relevante. Por un lado, los países exportadores han seguido una política restrictiva de cuotas de producción en el marco del cartel de la OPEP, cuyos mayores éxitos se vivieron en la década de los setenta, en la que el precio del petróleo, desde un punto de partida de 2 dólares por barril, llegó a superar ampliamente los 30 dólares por barril, y que en los dos últimos años ha vuelto a recuperar algo de su esplendor perdido aprovechando la mayor demanda derivada de la bonanza del ciclo americano y europeo para tensionar el mercado. Por el otro, como respuesta, los países occidentales han introducido impuestos específicos que estimulan el ahorro energético y han intentado diversificar sus fuentes energéticas para reducir su hasta ahora excesiva dependencia del encarecido petróleo, con el consiguiente relajamiento en sus precios durante gran parte de la década de los años ochenta y noventa.

El gran cambio en la relación real de intercambio entre el mundo islámico y occidental y la consiguiente redistribución de riqueza, se producen a partir de la gran subida de los precios de los años setenta, ya que los países consumidores se vieron obligados a dedicar una mayor parte de su producción para obtener la misma cantidad de petróleo que antes. Para que ésta se produjera fue necesario que los países productores actuaran conjuntamente como un bloque, lo cual sólo fue posible tras la utilización del petróleo como arma política ante el fracaso militar de la guerra árabe-israelí de 1973. El embargo de los suministros petrolíferos a los países occidentales que más apoyaron entonces al Estado judío tensionó el mercado, con lo que los precios se multiplicaron en poco tiempo, con lo que se evidenció que en el corto plazo la demanda era totalmente rígida e insensible al precio y que potenciar el cartel de la OPEP beneficiaba a todos sus integrantes.

Aunque el interés conjunto de los países productores es elevar los precios del petróleo que venden al resto del mundo, algunos países tienen intereses específicos propios, como Arabia Saudí y Kuwait, que son los países del Golfo Pérsico que más dependen de la protección militar estadounidense ante su vulnerabilidad frente a sus expansionistas vecinos. La política de estos países es especialmente delicada ya que han de conciliar sus intereses económicos, en el corto plazo, de mantener alto el precio del petróleo con los condicionantes políticos de no afrentar en exceso al mundo occidental, del que depende la supervivencia de sus regímenes. Esta contradicción se resuelve en la práctica adoptando una posición más sensible y atemperadora del equilibrio en los momentos de tensión excesivos de los mercados petrolíferos, aumentando su capacidad de producción, como sucedió excepcionalmente en los momentos previos a la guerra del Golfo o después de los atentados del 11 de septiembre.

El declive macroeconómico cono consecuencia de los shocks petrolíferos de 
1973 y 1979 corroborará el impacto negativo de una fuerte elevación de los precios del petróleo en términos de pérdida de actividad y empleo. En este sentido basta citar, a título de ejemplo, que siete de las ocho recesiones sufridas en EE.UU. tras la Segunda Guerra Mundial habían estado precedidas generalmente, y con un retardo entre tres trimestres y un año, por fuertes alzas en el precio del petróleo. La elevación de precios del input petrolífero incide en la actividad económica de un país dependiente del mismo, ya que provoca una perturbación negativa de oferta, por la que el aumento de los costes energéticos origina una caída de la producción, precisamente de aquella que resulta menos competitiva con la nueva estructura de costes relativos, y un aumento en los niveles de precios y en los déficit comerciales.

\section{EL ACERCAMIENTO DE OCCIDENTE Y EL ISLAM COMO RESPUESTA AL TERRORISMO FUNDAMENTALISTA E IMPULSO AL DESARROLLO}

La dialéctica demagógica de contraponer el crecimiento del mundo desarrollado con el de los países árabes es una falacia que, además, tiene los perniciosos efectos económicos de justificar los errores internos de política económica. De hecho, si tenemos en cuenta la creciente interdependencia comercial y financiera a nivel mundial, la convergencia en renta de los países árabes sólo se podrá producir en las etapas alcistas de los países occidentales, ya que en los momentos recesivos las brechas de crecimiento entre ambos mundos en plazos lo suficientemente largos no se acortan, sino que se agrandan. Así, según nuestros cálculos, en los últimos ocho años los ciclos económicos de los países occidentales y los del Norte de África y Oriente Medio han estado positivamente correlacionados en un orden del 50 por 100 , con lo se puede afirmar que la prosperidad occidental contribuye también a la prosperidad del mundo islámico a través de su incidencia positiva en la configuración de los precios del petróleo (vid. cuadro en página siguiente).

Estas conexiones hacen que el terrorismo contra Occidente pueda acabar volviéndose en contra del mundo islámico al precipitar su empobrecimiento. La principal vía es la de la reducción de la demanda de petróleo resultante del menor nivel de crecimiento que supone el shock de oferta del terrorismo, que aumenta el nivel de incertidumbre y los costes de transacción de los agentes: primas de seguros, transporte, fletes, etc. Pero no es la única vía; los mayores riesgos de pérdida de capital físico y humano derivados del terrorismo reducen el flujo internacional de inversión recibida por los países de confesión islámica (sólo del orden del 1 por 100 del total mundial) y estimulan permanentemente la salida de capitales hacia otros países más estables y con menores riesgos. El terrorismo también contrae especialmente los flujos turísticos, como está sucediendo con los viajes aéreos y con el abandono de destinos percibidos como conflictivos. De igual forma, con la prioridad de la seguridad interna se cierran 


\begin{tabular}{|c|c|c|c|c|c|c|c|c|c|c|}
\hline & 1993 & 1994 & 1995 & 1996 & 1997 & 1998 & 1999 & 2000 & 2001 & $\begin{array}{l}\text { Media } \\
\text { periodo }\end{array}$ \\
\hline Occidente ................... & 0,8 & 2,7 & 2,1 & 2,3 & 2,8 & 2,1 & 2,8 & 3,6 & 1,4 & 2,3 \\
\hline $\begin{array}{l}\text { Oriente Medio y Norte } \\
\text { de África .................... }\end{array}$ & 1,5 & 2,2 & 2,5 & 4,8 & 4,1 & 4,3 & 2,7 & 4,5 & 4,9 & 3,5 \\
\hline
\end{tabular}

FUENTE: Fondo Monetario Internacional.

las puertas a la emigración, con la consiguiente merma de las remesas de emigrantes para financiar los déficit comerciales y los procesos de acumulación de capital. Por todo ello, tanto la civilización occidental como la islámica son víctimas de la violencia terrorista y de la utilización de la fuerza con la excusa de la religión.

De hecho, ante los atentados del 11 de septiembre se produjo una reacción de rechazo y condena expresos, con declaraciones por parte de la Liga Árabe y de la Conferencia Islámica, que refleja el distanciamiento político de los árabes moderados respecto al terrorismo. Aunque, desde el punto de vista estrictamente de la seguridad de Occidente, parece razonable funcionar bajo el principio general de que las agresiones nunca queden impunes y que cualquier acción violenta se vuelva siempre en contra de quien la promueve, ante el rechazo unánime y conjunto de la comunidad internacional. También es cierto que cualquier acción de represalia o represión, por muy justificada que esté moralmente, si es desproporcionada o se salda con un alto coste de vidas humanas, puede tener la consecuencia perversa de avivar de nuevo la espiral de violencia, con lo que se ha de alcanzar el equilibrio entre los resultados militares y evitar al máximo las pérdidas de vidas humanas inocentes, tal y como parece se ha alcanzado en la campaña de Afganistán.

El mundo occidental puede utilizar la economía como instrumento, de medio y largo plazo, para socavar las bases del terrorismo islámico, desde una perspectiva positiva de cooperación más que negativa de destrucción, y más anticipándose a los acontecimientos que reaccionando defensivamente a los mismos (Haynes, 2000), lo cual pasa necesariamente por aumentar los vínculos económicos y compromisos entre ambos mundos y fomentando el desarrollo económico y la vertebración social en los países árabes. Si bien las agresiones de los grupos terroristas fundamentalistas pueden provocar un rechazo indiscriminado del mundo occidental hacia el mundo islámico, no se debe caer en el error de reducir nuestra apertura comercial, la generosidad con la emigración o la ayuda al desarrollo, ya que contribuyen a desarmar las bases del terrorismo.

La solidaridad no sólo es moralmente deseable, sino que también es racional en la medida en que puede alterar los costes y los beneficios relativos del 
posible enfrentamiento con Occidente si se utiliza para discriminar positivamente a los países islámicos que respetan las reglas del juego del orden internacional de convivencia pacífica y respeto a los derechos humanos. En este punto, España tiene una especial responsabilidad ya que constituimos la frontera europea más cercana con el mundo islámico y, por lo tanto, debemos impulsar la cooperación en el Mediterráneo iniciada en el proceso de Barcelona de noviembre de 1995 (Ghilès, 2001).

En definitiva, libertad, tolerancia respecto al Estado de Derecho y colaboración son las principales herramientas disponibles para impulsar el desarrollo y evitar situaciones de radicalismo. Sólo con la comprensión y el esfuerzo conjuntos se superará necesariamente la dualidad actual entre Occidente y el Mundo Islámico.

\section{BIBLIOGRAFÍA}

BAnco Mundial (2001): Informe para el desarrollo mundial: instituciones para los mercados, Ediciones Mundi-Prensa, Madrid.

Friedman, T. L. (1999): Tradición versus innovación. Buscar el equilibrio en la era de la globalización, Editorial Atlántida, Buenos Aires.

GARAUDY, R. (2001): Los integrismos. Los fundamentalismos en el mundo, Editorial Gedisa, Barcelona.

GHILÈs, F. (2001): «Reactivar el proceso de Barcelona», en el núm. 84 de la Revista Política Exterior, monográfico sobre Enemigo difuso: no es el islam; ni Afganistán...

HAYNES, M. (2000): World of risk: next generation strateggy for a volatile era, Willey \& Sons, Singapur.

Huntington, S. P. (2001): El choque de civilizaciones y la reconfiguración del orden mundial, Paidós, Barcelona.

Kepel, G. (2001): La Yihad: expansión y declive del islamismo, Ediciones Península, Barcelona.

Martínez, P. (1997): El reto del islam. La larga crisis del mundo árabe contemporáneo, Ediciones Temas de Hoy, Madrid.

Miguel, C. J. (2000): «La factura de defensa», en Claves de Economía Mundial, ICEX, Madrid.

SACHS, J. D. (2002): «Culpar al islam es demasiado fácil», artículo publicado en el El País Negocios del 13 de enero.

SEN, A. (2000): Desarrollo y libertad, Planeta, Barcelona. 